\title{
Tekrarlayan Akciğer Enfeksiyonu ve Dirençli Demir Eksikliği Anemisi Ayırıcı Tanısında Nadir Bir Antite: İdiyopatik Pulmoner Hemosiderozis
}

\author{
A Rare Entity in the Differential Diagnosis of Recurrent Pulmonary \\ Infection and Refractory Iron Deficiency Anemia: Idiopathic \\ Pulmonary Hemosiderosis \\ Mustafa BÜYÜKAVCI ${ }^{1}$, Olena ERKUN²${ }^{2}$, Mehmet Fatih ORHAN ${ }^{1}$
}

'Sakarya Üniversitesi Tıp Fakültesi, Çocuk Sağlığı ve Hastalıkları Anabilim Dalı, Çocuk Hematoloji-Onkoloji Bilim Dalı, Sakarya, Türkiye

22Sakarya Üniversitesi Tıp Fakültesi ,Çocuk Sağlığı ve Hastalıkları Anabilim Dalı, Sakarya, Türkiye

\begin{abstract}
öz
İdiyopatik pulmoner hemosiderozis (IPH), demir eksikliği anemisi (DEA), tekrarlayan alveoler hemoraji atakları ve hemoptizi ile seyreden ve etyolojisi tam bilinmeyen nadir bir hastalıktır. Olguların büyük çoğunluğu çocukluk döneminde görülür. Klinik olarak hemoptizi, alveoler hemoraji atakları sırasında gelişen solunum sıkıntısı, akciğer grafisinde parankimal infiltratlar ve sekonder demir eksikliği anemisi gibi bulgularla prezente olur. Bu nedenle de tekrarlayan solunum sıkıntısı ve demir eksikliği anemisine neden olan diğer hastalıklarla ayırıcı tanısı yapılmalıdır. Biz burada tekrarlayan alt solunum yolu infeksiyonu ve kistik fibrozis ön tanısıyla izlenen ve IPH tanısı alan iki yaşındaki bir olguyu sunuyoruz. Olgunun tanısı bronkoalveoler lavaj sıvısında hemosiderin yüklü makrofajlar görülerek doğrulanmış ve steroid tedavisi ile remisyon sağlanmıştır.
\end{abstract}

Anahtar Sözcükler: Demir eksikliği anemisi, Kistik fibrozis, Pulmoner hemosiderozis

\begin{abstract}
Idiopathic pulmonary hemosiderosis $(\mathrm{IPH})$ is a rare disorder of unknown etiology and characterized with iron deficiency anemia (IDA), recurrent attacks of alveolar hemorrhage and hemoptysis. The vast majority of cases occur during childhood. Clinically, it is presented with symptoms such as hemoptysis, respiratory distress during attacks of alveolar hemorrhage, parenchymal infiltrates on chest x-ray and secondary iron deficiency anemia. Therefore, differential diagnosis should be done to rule out other diseases causing recurrent respiratory distress and iron deficiency anemia. We present a 2-year-old patient with a history of recurrent lower respiratory tract infection and cystic fibrosis who was diagnosed with $\mathrm{IPH}$. The diagnosis of the case was confirmed by seeing hemosiderin-laden macrophages in bronchoalveolar lavage fluid. Remission was achieved with steroid treatment.
\end{abstract}

Key Words: Iron deficiency anemia, Cystic fibrosis, Pulmonary hemosiderosis

\section{GiRiş}

İliyopatik Pulmoner Hemosiderozis ( $\mathrm{PH})$ patogenezisi ve etyolojisi bilinmeyen kronik, tekrarlayan alveoler hemoraji atakları ile seyreden nadir bir hastalıktır. IPH, hemoptizi, akciğer grafisinde diffüz parankimal infiltrasyon ve sekonder demir eksikliği anemisinin (DEA) birlikte olduğu bir klinik triaddır.
Ancak hastaların hepsinde bașvuru sırasında klasik triad gözlenmemektedir (1-3). Bu hastallk ilk defa 1864 yllinda Rudolf Virchow tarafından postmortem olgularda tanımlanmış ve ilk klinik olgu 1931'de yayınlanmıştır (1,3). Hemoraji atakları sonucunda demir eksikliği anemisi ve hemosiderin birikimine bağlı akciğerde fibrozis gelişebilmektedir. Akut hemoraji atağı sırasında akciğer grafisinde bilateral alveoler infiltrasyonlar ve BT'de buzlu cam opasitesi olan alanlar görülebilmekte; balgam,
(1)

BÜYÜKAVCI M: 0000-0002-9054-3134 ERKUN O : :0000-0003-3067-3794 ORHAN MF : :0000-0001-8081-6760
Çıkar Çatışması / Conflict of Interest: : Tüm yazarlar adına, ilgili yazar çıkar çatışması olmadığını belirtir.

Finansal Destek / Financial Disclosure: Yazarlar bu olgu için finansal destek almadıklarını beyan etmișlerdir.

Onay / Confirmation: Kayıt sırasında veliler tarafından araştırmaya katııı için bilgilendirilmiş bir onay imzalanmışıı.

Atıf yazım şekli / How to cite : Büyükavcı M, Erkun O, Orhan MF. Tekrarlayan Akciğer Enfeksiyonu ve Dirençli Demir Eksikliği Anemisi Ayırıı Tanııında Nadir Bir Antite: Idiyopatik Pulmoner Hemosiderozis. Türkiye Çocuk Hast Derg 2020;14:531-535. 
bronkoalveoler lavaj ya da gastrik lavaj SIVISı incelemesinde hemosiderin yüklü makrofajlar saptanarak tanı doğrulanmaktadır. Klinikte başvuruların çoğunluğu demir eksikliği anemisi nedeni ile olmaktadır. Ancak etyoloji bilinmediği ve çok farklı klinik tabloyla gelebildiği için tanı koymak zordur ve tanıda gecikme olabilmektedir. Olguların \%80'i çocukluk çağında tespit edilip insidansı 0.24-1.23 vaka/milyon olarak bildirilmektedir. Çoğunlukla bir ile yedi yaş arası çocuklarda rastlanmakta ve 15 yıllık sağkalım oranı \%50'ye kadar düşebilmektedir (1-3). Tanı için yardımcı bulgular tekrarlayan demir eksikliği anemisi yanı sıra kronik öksürük, hemoptizi, dispne ve wheezing ataklarıdır. Bazı olgular, hiç akciğer bulgusu olmadan ara ara kan transfüzyonu yapılmasını gerektirecek kadar persistan ve tedaviye dirençli demir eksikliği anemisi ile seyredebilmektedir (2).

Kistik fibrozis (KF), çocuklarda ağır kronik akciğer hastalığı nedenlerinden birisidir (4). Kistik fibrozis transmembran regülator (KFTR) olarak adlandırılan ve epiteliyal hücrelerde klor iyonu transportundan sorumlu olan proteindeki fonksiyon bozukluğuna bağlı görülmektedir. Bu bozukluğun derecesine göre birçok sitemi ilgilendiren, özellikle havayolları, gastrointestinal sistem, böbrekler ve ter bezlerinde değişen ağılıkta bulgular ortaya çıkmaktadır. Etkilenen çocuklarda yağ ve protein emilimindeki bozulma nedeniyle büyüme ve gelişme geriliği, kronik respiratuar enfeksiyonlarla birlikte bronşiektazi, reaktif havayolu hastalığı, hemoptizi ve hepatobilier bulgular görülebilmektedir $(4,5)$. Bu nedenle de benzer bulgular gösteren birçok çocukluk çağı hastalıklarıyla karışabilmektedir. Özellikle tekrarlayan alt solunum yolu sorunları, büyüme geriliği ve hemoptizi gibi bulgular kronik alveoler hemorajiye neden olan pulmoner hemosiderozis gibi hastalıklarda da görülebilmektedir. Biz burada tekrarlayan alt solunum yolu infeksiyonu ve kistik fibrozis ön tanısıyla izlenen ve IPH tanısı alan bir olguyu sunuyoruz.

\section{OLGU SUNUMU}

İki yaşında erkek hasta üç aydır tedavi almasına rağmen düzelmeyen anemi ve üç gündür devam eden nefes darlığı şikayetleri ile başvurdu. Hastanın özgeçmişinde dokuz ay önce ağır anemi (Hemoglobin $3.1 \mathrm{~g} / \mathrm{dL}$ ) nedeniyle eritrosit süspansiyonu verildiği, sonraki takiplerinde 5-6 ay süreyle hemoglobin değerinin 10-11 g/dL arasında seyrettiği anlaşıldı. Ancak üç ay önce solukluk ve büyüme geriliği yakınmalarıyla tekrar polikliniğe başvurduğu ve tam kan sayımında WBC 11500/ $\mathrm{mm}^{3}$, trombosit 468000/ $\mathrm{mm}^{3}$, hemoglobin $5.9 \mathrm{~g} / \mathrm{dL}$, MCV 67.1 fL, MCH 19.2 pg, MCHC $29.7 \mathrm{~g} / \mathrm{dL}, \mathrm{RBC} 3.08 \times 106 / \mathrm{mm}^{3}$ ve RDW \%21 olarak tespit edilerek demir eksikliği anemisi tanısıyla oral demir tedavisi (5 mg/kg/gün) başlandığı öğrenildi. Ayrıca hastanın tekrarlayan alt solunum yolu infeksiyonu nedeniyle izlendiği, kistik fibrozis ön tanısıyla iki kez tekrarlanan ter testi sonucunun sınırda pozitif olarak (62 mEq/L, N: 40-60 mEq/L) rapor edildiği için genetik test istendiği, ancak CFTR genindeki varyasyonların tespiti için Multiplicom CFTR Mastr Dx yeni nesil dizileme kiti ve Illumina MiSeq sistemi kullanılarak yapılan dizi

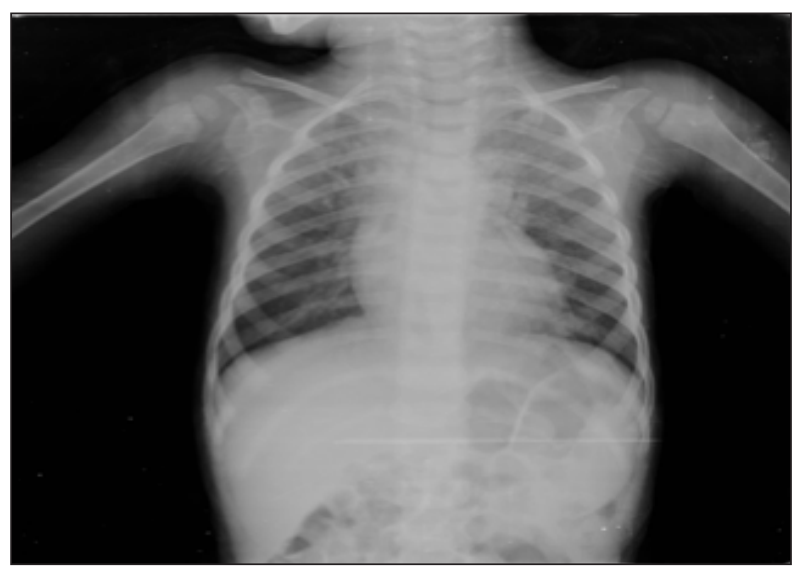

Resim 1: PA Akciğer grafisinde bilateral alveoler infiltrasyon.

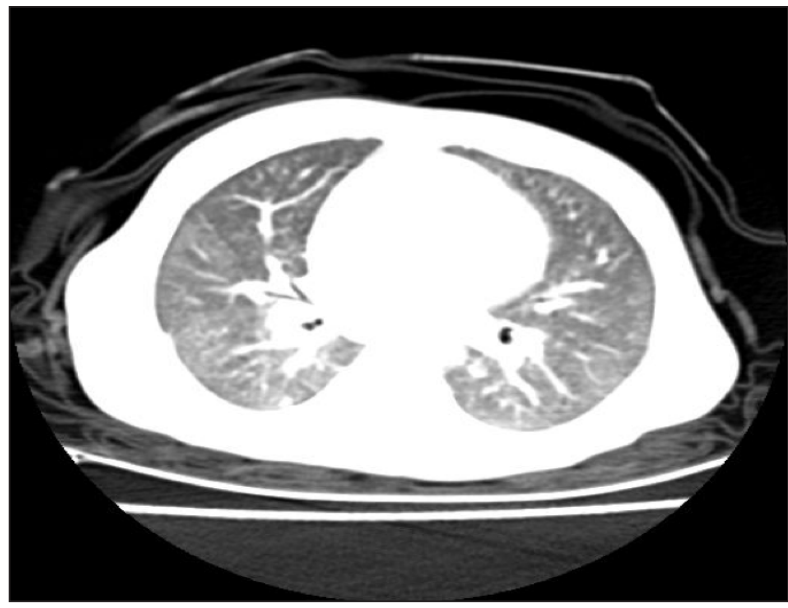

Resim 2: PA Akciğer grafisinde bilateral alveoler infiltrasyon.

analizi sonucunda CFTR geninde mutasyon saptanmadığı belirtildi. Soy geçmişinde anne-baba arasında akraba evliliği olmadığı ve bir abisinin sağ ve sağlıklı olduğu ifade edildi.

Fizik muayenede genel durum orta, cilt ve mukoza soluk, bilateral akciğer sesleri azalmış, kalp tepe atımı ritmik olup 2/6 sistolik üfürüm vardı. Diğer sistemlerin muayenesi normaldi. Vücut sıcaklığı $37.8^{\circ} \mathrm{C}$, solunum sayısı 44-48/dk, kalp tepe atımı 120-124/dk ve SpO2 \%88-91 olan hastanın vücut ağırlığı 9 kg (<3 persantil) ve boyu 82 cm (3-10 persantil) ölçüldü. Laboratuvar incelemesinde WBC 9900/ $\mathrm{mm}^{3}$, trombosit 369 000/mm³, hemoglobin $5.95 \mathrm{~g} / \mathrm{dL}, \mathrm{MCV} 67.8 \mathrm{fL}, \mathrm{MCH} 18.5$

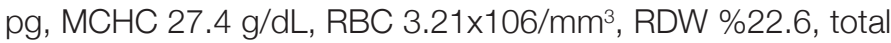
demir bağlama kapasitesi 279 mcg/dL, serum demiri 6 mcg/ dL, ferritin 109 mcg/L, LDH 591 U/L, CRP 8.7 mg/L ve eritrosit sedimentasyon hızı 11/saat saptandı. Karaciğer ve böbrek fonksiyon testleri, tam idrar analizi, protrombin zamanı ve aktive parsiyel tromboplastin zamanı normal sınırlardaydı.

Demire dirençli demir eksikliği anemisi (IRIDA), tekrarlayan akciğer enfeksiyonu, kistik fibrozis, immün yetmezlik sendromu ön tanılarıyla hastaneye yatırılan hastanın nazal sürüntü PCR örneğinde bakılan solunum panelinde Respiratuar Sinsisyal Virüs PCR pozitif saptanırken, kan kültüründe üreme olmadı. İmmunglobulin $\mathrm{G}$, A ve $\mathrm{M}$ düzeyleri yaşa göre normal aralıkta 


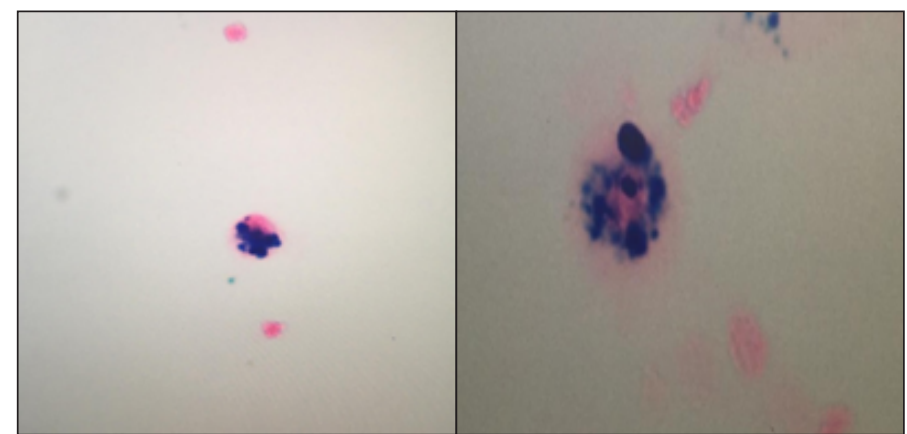

Resim 3: Bronkoalveoler lavaj sıvısında hemosiderin yüklü makrofajlar.

raporlanırken çekilen akciğer grafisinde bilateral yer yer konsolide alanlar izlendi (Resim 1). Bilgisayarlı tomografide ise her iki hemitoraksta yer yer buzlu cam görüntüleri ve pnömonik infiltrasyonlar saptandı (Resim 2). Hastaya intravenöz ampisilin-sulbaktam (150 mg/kg/gün), oral klaritromisin (15 mg/kg/gün) ve oral oseltamivir (4 mg/kg/gün) tedavisi başlandı. Derin anemisi ve solunum sıkıntısı nedeniyle bir kez eritrosit süspansiyonu transfüzyonu yapıldı. Yatışının beșinci gününde genel durumu iyi, vital bulguları normal aralıklarda ve hemoglobini $10.5 \mathrm{~g} / \mathrm{dL}$ olan ve șikayeti olmayan hasta taburcu edildi. Ancak hastanın öyküsü ve bașvurudaki klinik bulguları ışığında hastadaki bulguların tekrarlayan alveoler hemoraji ataklarına bağlı olabileceği düşünüldü. Açlık mide suyu ve bronkoalveoler lavaj örnekleri alınarak Prusya mavisi ile boyandı. Direk bakıda bronkoalveoler lavaj sıvısında hemosiderin yüklü makrofajlar görüldü (Resim 3). Ayııııı tanı açısından bakılan Anti-Nükleer antikor (ANA), Anti-dsDNA, Antikardiolipin IgM ve IgG, Anti-Endomisyum Antikorları IgA/G, Anti Gliadin Ig A, doku transglutaminaz $\lg A$ ve inek sütü hipersensitivitesi testleri (Spesifik lgE: inek sütü, alfa laktalbumin, beta laktoglobulin ve kazein) negatif tespit edildi. Elektrokardiyografi ve ekokardiyografi normal olarak rapor edildi. Taburcu olduktan üç hafta sonra üç gündür devam eden hırıltı, nefes darlığı, halsizlik ve solukluk şikayetleri ile tekrar başvuran hasta yatırldı. Fizik muayenesinde cilt ve mukozalar soluk olan hastanın solunum sayısı 44-66/ dakika, kalp tepe atımı 122-130/dakika, SpO2 \%70-90 ve 2/6 sistolik üfürüm mevcuttu. Akciğer grafisinde yaygın bilateral alveoler infiltrasyon görüldü (Resim 4). Laboratuvar tetkiklerinde hemoglobin $7.6 \mathrm{~g} / \mathrm{dL}, \mathrm{MCV} 78 \mathrm{fL}, \mathrm{MCH} 23.8 \mathrm{pg}, \mathrm{MCHC} 30.6$ g/dL, RDW \%24, RBC 3.2×109/mm³, CRP 58 mg/L, retikülosit \%3.3 ve LDH 817 U/L olarak raporlandı. Nazal kanül ile oksijen tedavisi bașlandı. Hasta idiyopatik pulmoner hemosiderozis olarak değerlendirildi ve steroid tedavisine bașlandı. Üç günlük intravenöz metilprednizolon (20 mg/kg/gün) tedavisinden sonra oral prednizolon (2 mg/kg/gün) ile devam edildi. Yatışıını dördüncü gününde solunum sıkıntısı azaldı, oksijen satürasyonu oda havasında \%96-98 ve akciğer grafisinde infiltrasyon belirgin azalmış olarak izlendi. Yedinci günde hemoglobin $8.8 \mathrm{~g} / \mathrm{dL}$ ve $\mathrm{CRP}<3 \mathrm{mg} / \mathrm{L}$ olan hasta taburcu edildi. On beșinci gün kontrolünde genel durum iyi olan solunum sıkıntısı olmayan ve hemoglobin değeri $8.8 \mathrm{~g} / \mathrm{dL}$ ölçülen hastanın prednizolon dozu $1 \mathrm{mg} / \mathrm{kg} / \mathrm{gün}$ olarak düzenlendi. Tedavinin birinci ayında hemoglobin $9.3 \mathrm{~g} / \mathrm{dL}$, retikülosit \%2, ferritin $32 \mathrm{mcg} / \mathrm{dL}$ ve LDH

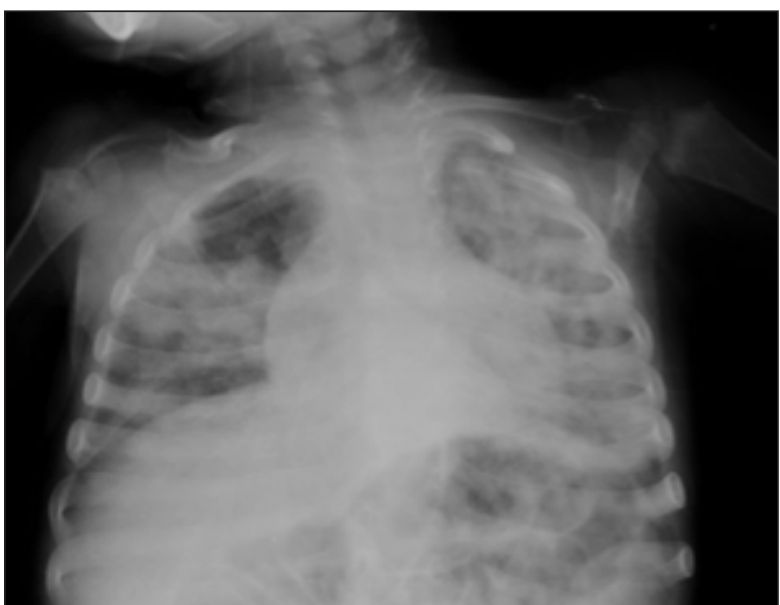

Resim 4: PA Akciğer grafisinde yaygın alveoler infiltrasyon alanları.

$264 \mathrm{U} / \mathrm{L}$ olup yakınması olmayan hasta $1 \mathrm{mg} / \mathrm{kg} / \mathrm{gün}$ dozunda prednizolon tedavisine devam etmektedir. Hastanın ayllk kontrollerle değerlendirilmesi, hemoglobin değerinin normal sınırlara ulaşması durumunda prednizolon dozunun $0.5 \mathrm{mg} /$ $\mathrm{kg} / \mathrm{gün}$ dozuna düșülerek 18 ay süreyle devam edilmesi, bu süre zarfinda steroid tedavisinin olası yan etkileri (infeksiyonlar, gelişme geriliği, aseptik nekroz, katarakt vs.) açısından izlenmesi planlanmaktadır. İzlem sırasında pulmoner hemoraji atağı gözlenmezse 18 ayın sonunda tedavinin kesilmesi düşünülmektedir.

\section{TARTIȘMA}

İliyopatik pulmoner hemosiderozis, "diffüz alveoler hemoraji" ile seyreden hastalıklar arasında yer almaktadır. Tekrarlayıcı intraalveoler hemoraji atakları sonucunda alveoler makrofajlara demirin hemosiderin olarak anormal birikmesiyle karakterize, birçoğu çocukluk çağında görülen ve etyolojisi aydınlatılamamış bir hastalıktır. Tam patogenezi bilinmediğinden alveoler hemoraji etyolojisinde başka bir hastalığın bulunamadığı durumlarda düșünülmekte ve ekartasyon tanısı olarak konulmaktadır $(1,6)$. Hastalığın klasik klinik bulgularını hemoptizi, demir eksikliği anemisi ve akciğer filminde çok sayıda alveoler infiltratların gözlendiği triad olușturmaktadır. Ancak hem her olguda bu bulguların birlikte olmaması hem de aynı bulgularla seyredebilen pek çok hastalık bulunması nedeniyle tanılar gecikebilmektedir.

Idiyopatik pulmoner hemosiderozisde semptomlar pulmoner hemorajinin miktarına bağılır. Hastalık semptomsuz șekilde olabileceği gibi şok ve ölüme kadar ilerleyen klinik tablolar da olușturabilir $(1-3,6)$. Kanama epizodları sonrasında hasta hışıltı, öksürük, hemoptizi ve solunum sıkıntısı ile başvurabilir ve fizik muayenede tașikardi, tașipne, solukluk, ateș, göğüs retraksiyonu, ral ve ronküsler saptanabilir. Eğer masif kanama varsa solunum yetmezliği ve șok tablosu gelișebilir. Bazı çocuklar kanama atakları arasında sadece anemi ve büyüme geriliği șikâyetleri ile bașvurabilmektedir $(1,2,7)$. Bizim olgumuz da tekrarlayan hıșıltı, tașipne, solukluk ve ateş yakınmalarıla 
başvurduğu için öncelikle reaktif hava yolu hastalığı, bronşiolit ve altta yatan immün yetmezlik sendromları-kistik fibrozis gibi tanılar düşünülmüştü. Solukluğun nedeni olan ağır hipokrommikrositer anemi ve büyüme geriliği ise altta yatan kronik hastalığa ve nutrisyonel demir eksikliğine bağlanmıştı. İki yaşında olmasına rağmen ağırlıkı olarak anne sütüyle beslenen ve öncesinde demir profilaksisi almamış olan hastamızda bu ön tanılar makul gözükmektedir. Ancak hastamızda laboratuvar olarak ağır hipokrom-mikrositer anemi ve serum demir düzeyinde düşüklük olmasına rağmen serum ferritin düzeyinin yüksek ölçülmesi uyarıcı bir faktör olabilirdi. Bununla birlikte, eșlik eden infeksiyonların da ferritin düzeyinin yüksek olmasına katkıda bunabileceği akılda tutulmalıdır.

Laboratuvarda klasik olarak hipokrom-mikrositer anemi, retikülositoz, azalmış serum demiri ve genellikle artmış demir bağlama kapasitesi beklenir $(1,2)$. Ancak IPH'de alveol içine kanama sonucu ortaya çıkan demir, makrofajlar tarafindan tutulduğu için tablo daha çok kronik hastallı anemisini andııır şekildedir. Yani azalmış ya da normal demir bağlama kapasitesi ile birlikte ferritin düzeyi de normal veya artmış olabilir (8). Bizim hastamızda da düșük demir düzeyiyle birlikte ağır anemi olmasına karşın serum ferritin düzeyi ve demir bağlama kapasitesi normal aralıktaydı. Bu olgular ayrıca alveollerdeki hemoglobinin parçalanması nedeniyle plazma bilirubin düzeyi yükselerek hemolitik anemiyi taklit edebilmektedir (1).

Hastamızın görüntülemelerinde pnömonik infiltrasyonlar ve buzlu cam görünümü rapor edilmişti. Literatürde bildirilen olguların radyolojik bulguları da interstisyel infiltrasyon, konsolidasyon, pulmoner nodüller, kavitasyon, fibrozis ve buzlu cam dansiteleri gibi nonspesifik değişikliklerdir $(1,2,7)$. Ancak pnömonik infiltrasyonlar, nodüler dansiteler ve atelektaziye ait görünümler kistik fibrozisli hastalarda da görülebilmektedir (4). Bu açıdan ayıııcı tanıda karışabilmektedir.

Alveolerhemoraji tanısı içinaltınstandartakciğer biyopsisiolmakla birlikte çoğunlukla daha az invaziv yöntemler kullanılmaktadır. Uygun klinik ve laboratuvar bulguların eşliğinde mide lavaj sıvisında ya da bronkoalveoler lavaj sıvısında hemosiderin yüklü makrofajların gösterilmesi tanı için yeterli olmaktadır $(1,2,6)$. Ancak bronkoalveoler lavaj sıvısının incelenmesi tanı açısından açlık mide sıvısına göre daha yüksek duyarlıı̆ga sahiptir: \%30'a karșı \%92 (2). Biz de bronkoalveoler lavaj sıvısında hemosiderin yüklü makrofajları gördüğümüz halde sabah alınan açlık mide sIVISInda tespit edemedik.

Diffüz alveoler hemorajiye neden olan ve IPH ile ayırıcı tanısı yapılması gereken pek çok klinik durum söz konusudur. Enfeksiyonlar, koagülopatiler, HSP ve Wegener granülomatozisi gibi sistemik vaskülitler, sistemik lupus eritematozus, Good Pasture sendromu, çölyak hastalığı, inek sütü allerjisi, pulmoner kapillaritis ve kardiyak sebeplerin dişlanması gerekmektedir. Bu antitelerin ayııımı için diğer laboratuvar testlerin yanı sıra hastanın yaşı, hastalığın ağılı̆̆ı, yapılacak işlemin sağlayacağı yarar ve olası komplikasyonları değerlendirilerek akciğer biyopsisi yapılması da gerekebilmektedir. Özellikle tipik klinik bulgularla başvuran çocuklar için biyopsiye gerek duyulmamakta, ancak tedaviye yanıt vermeyen olgularda transbronşiyal veya açık akciğer biyopsisi önerilmektedir. Hastamıza başvuru sırasındaki klinik bulgularıyla birlikte yukarıda belirtilen antitelerin ayrımı için yaptığımız laboratuvar testleri ve görüntülemelerin negatif olarak rapor edilmesi üzerine IPH tanısı konuldu. IPH'nın çölyak hastalığı (Lane-Hamilton sendromu) veya inek sütü hipersensitivitesi (Heiner sendromu) ile birlikteliği de söz konusudur $(9,10)$. Bizim hastamızda böyle bir birliktelik yoktu.

Kistik fibrozisli hastalar da benzer klinik, laboratuvar ve radyolojik bulgularla başvurabilmektedir. Tanı için aşağıdaki parametrelerden bir veya daha fazlasının eșlik ettiği ter testi pozitifliği (Klor $\geq 60 \mathrm{mEq} / \mathrm{L}$ ) yeterli görülmektedir: a) CFTR geninde mutasyonunun tanımlanması, b) Tipik kronik obstrüktif akciğer hastalığı, c) Ekzokrin pankreas yetmezliği, d) Pozitif aile öyküsü (4). Bizim olgumuzda tekrarlanan ter testinde sınırda pozitif sonuçlar elde edilmişti. Ancak büyüme geriliği gibi faktörlerin ter testi sonucunu etkileyebileceği bilindiğinden ve destekleyici ilave kriterlerin olmaması nedeniyle kistik fibrozis düșünülmedi. Bizim hastamızda yapılamamıș olmakla birlikte, CFTR genindeki büyük delesyon ve duplikasyonların tespiti için MLPA analizi gibi daha duyarlı yöntemlerin bulunduğu da akılda tutulmalıdır.

IPH tedavisinde destek bakım yanı sıra hemorajiye bağlı inflamasyonu azaltması ve geç dönemde gelişebilecek fibrozisi önlemesi amacıyla steroid tedavisi önerilmektedir. Metilprednizolon (2-4 mg/kg/gün) veya prednizolon (0.5-1 mg/ $\mathrm{kg} / \mathrm{gün})$ tedavisi semptomları azaltmakta, hemoraji ataklarının sıkığını azaltmaktadır. Klinik tablosu ağır olan hastalarda başlangıç tedavisi olarak üç günlük pulse metilprednizolon (5-30 $\mathrm{mg} / \mathrm{kg}$ ) gün, maksimum $1 \mathrm{~g}$ ) uygulaması da yapılabilmektedir (13,6). Biz hastamıza ikinci başvurusu sırasındaki belirgin solunum sıkıntısı, oksijen satürasyonu ve hemoglobin değerindeki belirgin düşüklük ve akciğer grafisindeki yaygın infiltrasyonlar nedeniyle pulse metilprednizolon tedavisi bașladık. Klinik olarak yanıt alınması üzerine dördüncü günde steroid dozunu 2 mg/kg/gün, 15 gün sonraki kontrolünde de $1 \mathrm{mg} / \mathrm{kg} / \mathrm{gün}$ olarak yeniden düzenledik. Tedavi süresi ile ilgili kesin bir bilgi olmadığı için de pulmoner semptomların olmadığı ve hemoglobin değerinin stabil olduğu en düşük dozda devam etmeyi planladık.

Sonuç olarak, tedaviye rağmen tekrarlayan demir eksikliği anemisi, büyüme geriliği ve tekrarlayan solunum sıkıntısı bulguları ile başvuran çocukların etyolojisinde diffüz alveoler hemoraji olabileceği ve dolayısılla IPH tanısı akılda tutulmalıdır.

\section{KAYNAKLAR}

1. Yajun Zhang, Fenglan Luo, Nini Wang, Yue Song et al. Clinical characteristics and prognosis of idiopathic pulmonary hemosiderosis in pediatric patients. J Int Med Res 2019;47:293302. 
2. Koker SG, Gözmen S, Oymak Y,Karapinar TH, Can D, Genç S, et al. Idiopathic pulmonary hemosiderosis mimicking iron deficiency anemia: a delayed diagnosis? Hematol Rep 2017; 9:7048.

3. Kabra SK, Bhargava S, Lodha R, Satyavani A, Walia M. Idiopathic pulmonary hemosiderosis: clinical profile and follow up of 26 children. Indian Pediatr 2007;44:333-8.

4. ME Egan, Michael S. Schechter, Judith A. Voynow. Cystic Fibrosis, In: R Kliegman, B Stanton, J St. Geme, NJ Blum, S Shah, R Tasker, K Wilson (eds), Nelson Textbook of Pediatrics, 21th Edition, Elsevier, Philadelphia 2020; 2282-97.e1.

5. Bell SC, Mall MA, Gutierrez H, Macek M, Madge S, Davies JC, et al. The future of cystic fibrosis care: a global perspective. Lancet Respir Med 2020;8:65-124.

6. MA Nevin. Pulmonary hemosiderosis, In: R. Kliegman, B. Stanton, J St Geme, NJ Blum, S Shah, R Tasker, K Wilson (eds), Nelson
Textbook of Pediatrics, 21th Edition, Elsevier, Philadelphia 2020; 2306-8.e1

7. Castellazzi L, Patria MF, Frati G, Esposito AA, Esposito S. Idiopathic pulmonary haemosiderosis in paediatric patients: how to make an early diagnosis. Ital J Pediatr 2016;42:86.

8. Minkov M, Kovacs J, Wiesbauer P, Dekan G, Gadner H. Severe anemia owing to occult pulmonary hemorrhage: a diagnostic pitfall. J Pediatr Hematol Oncol 2006;28:467-70.

9. Agarwal R, Aggarwal AN, Gupta D. Lane-Hamilton syndrome: simultaneous occurrence of coeliac disease and idiopathic pulmonary haemosiderosis. Intern Med J 2007;37:65.

10. Koc AS, Sucu A, Celik U. A different clinical presentation of Heiner syndrome: The case of diffuse alveolar hemorrhage causing massive hemoptysis and hematemesis. Respir Med Case Rep 2019;26:206-8. 